\title{
Localization of Transmissible and Nontransmissible Viruses in the Vector Nematode Xiphinema americanum
}

\author{
Shouhua Wang, Rose C. Gergerich, Sandra L. Wickizer, and Kyung S. Kim
}

Department of Plant Pathology, 217 Plant Science Building, University of Arkansas, Fayetteville 72701. Current address of S. Wang: Nevada Department of Agriculture, 350 Capitol Hill Avenue, Reno 89502. Accepted for publication 5 March 2002.

\begin{abstract}
Wang, S., Gergerich, R. C., Wickizer, S. L., and Kim, K. S. 2002. Localization of transmissible and nontransmissible viruses in the vector nematode Xiphinema americanum. Phytopathology 92:646-653.

The inner lining of the food canal of nematodes that transmit plantinfecting viruses is regarded as the retention region of viruses. To characterize the location of transmissible and nontransmissible viruses in the vector nematode Xiphinema americanum, three nepoviruses, Tobacco ringspot virus (TRSV), Tomato ringspot virus (TomRSV), and Cherry leaf roll virus (CLRV), and one non-nematode-transmissible virus, Squash mosaic virus (SqMV), were evaluated for transmission efficiency and localization sites in the nematode. Transmission trials showed highest transmission efficiency for TomRSV (38\% with 1 and 100\% with 10 nematodes, respectively), intermediate efficiency for TRSV (27\% with 1 and $65 \%$ with 10 nematodes, respectively), and no transmission for CLRV and SqMV. Electron microscopy and immunofluorescent labeling revealed that TRSV was primarily localized to the lining of the lumen of the stylet extension and the anterior esophagus, but only rarely in the triradiate lumen. Within a nematode population, particles of TRSV
\end{abstract}

ABSTRACT were no longer observed in these three regions 10 weeks after acquisition, and it is assumed that there was gradual and random loss of the virus from these areas. The percentage of nematodes that were labeled by virus-specific immunofluorescent labeling in a population of viruliferous nematodes decreased gradually after TRSV acquisition when the nematodes were placed on a nonhost of the virus, and the loss of immunofluorescent labeling paralleled the decrease in the ability of the nematode population to transmit the virus. TomRSV was localized only in the triradiate lumen based on thin-section electron microscopy. No virus-like particles were observed in any part of the food canal of nematodes that had fed on CLRV-infected plants. Virus-like particles that appeared to be partially degraded were observed only in the triradiate lumen of nematodes that had fed on SqMV-infected plants. These results clarified the status of localization of two nontransmissible viruses in X. americanum and presented evidence that two nematode-transmissible viruses, TRSV and TomRSV, are localized in different regions of the food canal of $X$. americanum.

Additional keywords: virus localization, virus-vector relationship.
A small number of species of plant parasitic nematodes of the Longidoridae and Trichodoridae are vectors of some viruses in the genera Nepovirus and Tobravirus, respectively. For a virus to be transmitted by a nematode, virus particles must be acquired and then retained in a specific area of the food canal by nematodes. Virus transmission occurs as a result of disassociation of retained virus particles from retention sites followed by direct injection of those viruses into plant root cells during nematode feeding. Virus retention and dissociation both govern the specificity and efficiency of virus transmission by nematodes (31). The process of nematode transmission of nepoviruses is apparently specific in that certain species of nematodes transmit one or a few nepoviruses but not others (4).

Nepoviruses are of significant economic importance (26). Tobacco ringspot virus (TRSV) and Tomato ringspot virus (TomRSV), like other members of the genus Nepovirus, infect a wide range of plants, including fruit crops and woody plants, resulting in substantial damage. Many economically important nepoviruses in North America are transmitted by nematodes in the genus Xiphinema (12).

$X$. americanum sensu stricto Cobb (5) is an ectoparasitic nematode that is widespread in North America (29). This species is associated with many types of fruit trees and transmits several important nepoviruses that include TRSV (8), TomRSV $(1,9)$, Cherry rasp leaf virus (27), and Peach rosette mosaic virus (19).

Corresponding author: R. C. Gergerich; E-mail address: gergeric@uark.edu

Publication no. P-2002-0412-01R

(C) 2002 The American Phytopathological Society
The relationship between North American indigenous nepoviruses and their vector Xiphinema species has been less studied than that between nepoviruses and their vectors that occur in Europe. Extensive research with nematodes and their associated viruses in Europe indicates that viral coat proteins $(13,14,28)$, a $29-\mathrm{kDa}$ nonstructural viral protein $(22,23)$, and carbohydrates $(30)$ in the food canal of nematodes play a significant role in determining specific retention of viruses in nematodes. The dissociation of virus particles from retention sites is proposed to be triggered by the $\mathrm{pH}$ change induced by nematode salivation (15). In contrast to the high degree of specificity observed in associations between European vectors and their associated viruses, the transmission of North American nepoviruses by Xiphinema spp. is reported to be less specific (3).

Revealing virus retention sites in a vector nematode is important to understand specificity of virus transmission. Previous studies with electron microscopy and immunofluorescent labeling indicated that the inner lining of the stylet extension and the esophageal lumen is the retention site for TRSV in $X$. americanum $(25,33)$. However, there is no information available on the retention sites for nepoviruses in X. americanum, or on the location of nontransmissible viruses in this nematode.

Indirect immunofluorescent labeling has been used to localize TRSV and monitor retention of TRSV in X. americanum (33). However, despite repeated efforts, we have not been successful using this technique for the detection of several other transmissible and nontransmissible viruses in nematodes from the same population. This may indicate that there are differences between TRSV and other nepoviruses in regard to their attachment and transmission by these nematodes. To characterize retention of both 
transmissible and nontransmissible viruses in $X$. americanum and help understand possible reasons why other viruses could not be detected with immunofluorescent labeling, we employed both immunofluorescent labeling (for TRSV only) and electron microscopy to reveal retention characteristics of TRSV, TomRSV, Cherry leaf roll virus (CLRV), and the non-nematode-transmissible Squash mosaic virus (SqMV) in the nematode X. americanum. The objectives of this study were to determine localization sites for both transmissible and nontransmissible viruses in the vector nematode $X$. americanum, and to compare the time course of transmission and dissociation of TRSV from different retention sites in X. americanum.

\section{MATERIALS AND METHODS}

Nematodes. Soil containing $X$. americanum from an apple orchard in northwestern Arkansas was collected periodically as needed throughout the course of the study. Populations of $X$. americanum that were confirmed to be nonviruliferous in our previous tests were extracted from soil by the modified sieving and decanting method combined with the Baermann funnel method (2). Freshly extracted $X$. americanum nematodes were used in all experiments.

Viruses. Viruses used in this study were reactivated from infected plant material that had been desiccated and stored at $4^{\circ} \mathrm{C}$. The viruses were maintained in the greenhouse by mechanical inoculation during the course of this study. TRSV was originally isolated from naturally infected 'Jersey' blueberry in southwestern Michigan (10) and maintained on cucumber (Cucumis sativus L. cv. Boston Pickling). TomRSV was isolated from naturally infected raspberry from Oregon (supplied by R. R. Martin, USDA, Corvallis, OR) and maintained on cowpea (Vigna unguiculata L. cv. Monarch). CLRV was isolated from naturally infected euonymus in Arkansas (21) and maintained on cucumber (Cucumis sativus L. cv. Model). SqMV was isolated from naturally infected squash in Arkansas and maintained on squash (Cucurbita pepo L. cv. Early Prolific Straightneck). The identity of the viruses used in this study was confirmed in gel double-diffusion immunoassays.

Transmission trials. To confirm the vector relationship between the four viruses and $X$. americanum, transmission tests were conducted in a growth chamber at 28 to $32^{\circ} \mathrm{C}$ with $12 \mathrm{~h}$ of illumination $\left(240 \mu \mathrm{mol} \mathrm{m} \mathrm{m}^{-2} \mathrm{~s}^{-1}\right)$. Procedures for transmission tests were described previously (33) and met the criteria of Trudgill et al. (32). For virus acquisition, cucumber cv. Model seedlings (four seedlings per beaker) were grown in 100-ml plastic beakers in fine river sand, and seedlings were mechanically inoculated with each virus during the cotyledon stage. When systemic symptoms of virus infection appeared, approximately 200 newly extracted $X$. americanum were added to each beaker around the roots of cucumber plants for acquisition feeding. Ten days later, the nematodes in each beaker were recovered, and a specified number of nematodes (Table 1) was added to the sand around the roots of single, young cucumber cv. Model bait plants growing in 25-ml plastic cups. After 3 weeks, to allow transmission to occur, the root system of each cucumber plant was washed with tap water and ground in $0.05 \mathrm{M}$ phosphate buffer, $\mathrm{pH} 7.2$, to generate root extract that was inoculated to indicator plants for each virus.

Immunofluorescent labeling of viruses in $X$. americanum. For virus acquisition, seedlings of cucumber cv. Model were mechanically inoculated with each virus and served as an acquisition source as described previously. Nematodes that had access for a period of 10 days to healthy cucumber plants or cucumber plants infected with each virus were recovered, and approximately 200 specimens were hand-picked and fixed in $2 \%$ formaldehyde for at least $24 \mathrm{~h}$. Nematodes were transferred to a glass slide and cut into small fragments of approximately $300 \mu \mathrm{m}$. Fragments were collected in a $1.5-\mathrm{ml}$ microcentrifuge tube, washed three times with blocking buffer $(0.14 \mathrm{M} \mathrm{NaCl}, 0.01 \mathrm{M}$ phosphate, $3 \%$ bovine serum albumin, and $0.2 \%$ Triton $\mathrm{X}-100, \mathrm{pH} 7.2$ ), and incubated with purified polyclonal antibody to TRSV that had been diluted 1:50 in blocking buffer. The antiserum against the 'Jersey' isolate of TRSV (10) was obtained by weekly subcutaneous injections of female New Zealand white rabbits with $2.0 \mathrm{mg}$ of purified virus emulsified in Freund's complete adjuvant (Difco Laboratories, Detroit) for the first injection and in Freund's incomplete adjuvant for subsequent injections. The virus was injected for a total of three times, and antiserum was collected for 4 weeks starting 1 week after the first injection. After incubation in the TRSV antiserum and washing in blocking buffer three times, the fragments were incubated for $20 \mathrm{~h}$ with fluorescein isothiocyanate (FITC)conjugated goat anti-rabbit immunoglobulin G (Sigma Chemical Co., St. Louis) diluted 1:50 in blocking buffer (33). After incubation, nematode fragments were washed four times in blocking buffer for $10 \mathrm{~min}$ each, dried in a vacuum dryer for $15 \mathrm{~min}$, mounted on glass slides in $10 \mu \mathrm{l}$ of $50 \%$ glycerol in phosphatebuffered saline, and observed under an epifluorescent microscope (BHT; Olympus Corporation, NY). Controls included immunofluorescent labeling of fragments from (1) viruliferous nematodes in the absence of the TRSV antiserum, and (2) nematodes that had been given access to healthy cucumber plants. Previously reported experiments using this immunofluorescent labeling technique for detection of TRSV in viruliferous $X$. americanum showed no immunofluorescent labeling when an antiserum to Cucumber mosaic virus was substituted for the TRSV antiserum (33).

Electron microscopy. About 50 specimens were hand-picked from nematode populations that had been given access to virusinfected acquisition plants and then fixed in Karnovsky's fixative (2\% glutaraldehyde and $2 \%$ paraformaldehyde in $0.05 \mathrm{M}$ cacodylate buffer, $\mathrm{pH} 7.2$ ) at $4^{\circ} \mathrm{C}$ for $24 \mathrm{~h}$. The head region of each nematode (from the anterior end to the base of the esophageal bulb) as shown in Figure 1 was excised in the fixative and washed twice in $0.05 \mathrm{M}$ cacodylate buffer for $20 \mathrm{~min}$ and postfixed in $1 \%$ osmium tetroxide (in $0.05 \mathrm{M}$ cacodylate buffer, $\mathrm{pH}$ 7.2) for $2 \mathrm{~h}$. The fixed specimens were washed twice in deionized water and en bloc stained in $0.5 \%$ uranyl acetate at $4^{\circ} \mathrm{C}$ overnight. About 10 to 15 nematode head regions were embedded in each block of $1 \%$ agar following the method of Hirumi et al. (16) with slight modifications. The melted agar was poured into a petri dish to form a 0.5-cm layer. After the agar solidified, a 3- to 4-mm hole was made in the agar and individual head regions were transferred to the bottom of the hole and arranged closely together and parallel to each other. A drop of melted $1 \%$ agar was added to fill the hole. Small pieces of agar block containing nematode heads in the center were cut from the agar and further trimmed to fit the embedding mold. Agar blocks were dehydrated in a series of ethanol solutions (15 min each in 30, 50, 70, 80, and 95\% and $15 \mathrm{~min}$

TABLE 1. Transmission of Tobacco ringspot virus (TRSV) and Tomato ringspot virus (TomRSV) and nontransmission of Cherry leaf roll virus (CLRV) and Squash mosaic virus (SqMV) by Xiphinema americanum to cucumber

\begin{tabular}{lccc}
\hline Virus $^{\mathrm{a}}$ & $\begin{array}{c}\text { No. of nematodes } \\
\text { per bait test }^{\mathrm{b}}\end{array}$ & $\begin{array}{c}\text { Transmission } \\
\text { frequency }\end{array}$ & $\begin{array}{c}\text { Percent } \\
\text { transmission }\end{array}$ \\
\hline TRSV & 1 & $26 / 98$ & $27 \%$ \\
TomRSV & 10 & $160 / 246$ & $65 \%$ \\
& 1 & $38 / 100$ & $38 \%$ \\
CLRV & 10 & $40 / 40$ & $100 \%$ \\
SqMV & 30 & $40 / 40$ & $100 \%$ \\
\hline
\end{tabular}

a Nematodes fed on virus-free plants did not transmit any virus tested (data not shown).

b Nematodes were picked from a population of nematodes that had fed on virus-infected cucumber cv. Model for 10 days, and these nematodes were transferred to bait cups that contained one cucumber plant per cup.

c The number of virus-infected bait plants / the number of total bait plants tested. Data are the combined results of two or more transmission trials with a minimum of 20 bait cups per trial. 


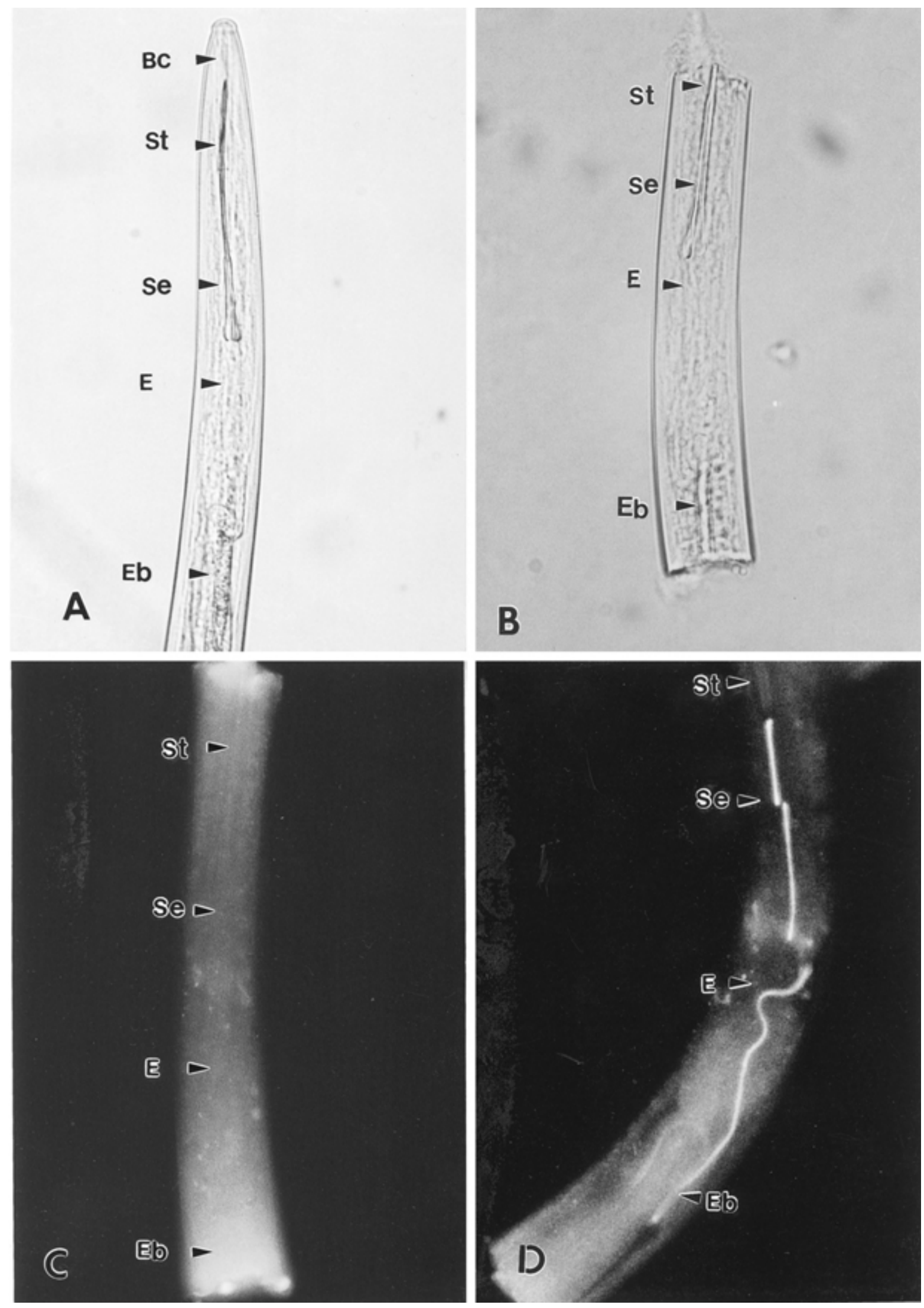

Fig. 1. Tobacco ringspot virus (TRSV)-specific immunofluorescent labeling in the esophageal tract of Xiphinema americanum. A, Light micrograph of head region of $X$. americanum showing bucal cavity (Bc), stylet (St), stylet extension (Se), anterior esophagus (E), and esophageal bulb (Eb). B, A light micrograph of a fragmented part of the head region of a nematode that had been given access to TRSV showing stylet (St), stylet extension (Se), anterior esophagus (E), and esophageal bulb $(\mathrm{Eb})$ prior to immunofluorescent labeling. $\mathbf{C}$, Fluorescent micrograph of a fragment similar to the one in $\mathbf{B}$, showing lack of immunofluorescent labeling in the control in which the TRSV antiserum was omitted. D, Fluorescent micrograph of a part of a head region of a viruliferous nematode treated with TRSV antiserum. TRSV-specific immunofluorescent labeling is clearly demonstrated in the stylet extension (Se), anterior esophageal lumen (E), and esophageal bulb (Eb). 
three times in $100 \%$ ethanol) followed by two changes in $100 \%$ propylene oxide for $15 \mathrm{~min}$ each. Agar blocks were then infiltrated with 50 and $75 \%$ Spurr's medium (vol/vol, diluted in propylene oxide) consecutively for $24 \mathrm{~h}$ followed by infiltration with $100 \%$ Spurr's medium for $24 \mathrm{~h}$ (two times with Spurr's medium replaced at $24 \mathrm{~h}$ ), and finally placed in Spurr's medium with the nematode heads oriented toward the tip of each mold. Molds were placed in a $70^{\circ} \mathrm{C}$ oven overnight for polymerization. Serial sections from the top of the head region to the end of the esophageal bulb were made and mounted on a series of numbered grids. One in every three grids was observed for presence of virus particles by transmission electron microscopy (100CX; JEOL, Tokyo). A total of 30 to 50 nematodes were examined for the presence of viruses in each group of nematodes having access to cucumber plants that were (i) virus-free, (ii) TRSV-infected, (iii) TomRSVinfected, (iv) CLRV-infected, and (v) SqMV-infected.

Time course of TRSV release from $X$. americanum. $X$. americanum were extracted from soil and about 300 nematodes were added to each $100-\mathrm{ml}$ plastic beaker in which three to four TRSV-infected cucumber plants were growing in fine river sand. After 10 days, the nematodes were recovered from the sand in which the acquisition plants were growing and pooled. Approximately 200 nematodes were used in a transmission trial as described above to determine the transmission efficiency of the nematode population. Another 200 nematodes were used in an immunofluorescent labeling experiment to determine the initial percentage of specimens displaying virus-specific fluorescence in the population. The remaining pooled nematodes were added to the sand around the roots of Sudan grass growing in 100-ml plastic beakers. Before the experiment, Sudan grass was determined to be a nonhost of TRSV but a favorable host for the nematode. Thus, the nematodes feeding on Sudan grass could release virus particles during feeding but would not cause infection of the Sudan grass. Nematodes were allowed to have access to roots of Sudan grass for 1, 2, 3, 7, and 10 weeks. At each time point, five beakers were randomly selected and the nematodes were recovered and pooled from these beakers. Recovered nematodes were divided equally into two groups, one used in a transmission trial to determine the transmission efficiency of the nematode population at that time point, and another in an immunofluorescent labeling experiment to determine the virus retention in the nematode population. The frequencies of fluorescence in regions of the stylet extension, anterior esophageal lumen, and esophageal bulb were recorded at each time point. This experiment was conducted twice.

\section{RESULTS}

Virus transmission. Both TRSV and TomRSV were transmitted by the nematode $X$. americanum. However, TomRSV was transmitted more efficiently than TRSV (Table 1). No transmission occurred with CLRV and SqMV when 30 nematodes that had fed on virus-infected cucumber plants were placed on the roots of each bait plant in transmission trials (Table 1). Field-collected populations of $X$. americanum used in these experiments did not transmit virus to cucumber bait plants based on infectivity assays of the bait plant roots, thereby confirming that these field populations were not carrying transmissible viruses that infect cucumber.

Application of immunofluorescent labeling to detect TRSV, TomRSV, CLRV, and SqMV in X. americanum. Viruliferous nematodes that had acquired TRSV were consistently labeled by the immunofluorescent labeling technique (Fig. 1). No virus-spcific FITC-fluorescent signals were observed in fragments from nematodes that had been given access to TRSV-infected cucumbers when TRSV antiserum was omitted from the immunofluorescent labeling procedure (Fig. 1B and C). Similarly, no immunofluorescent labeling occurred in fragments of nematodes that had fed on virus-free cucumber plants (data not shown).
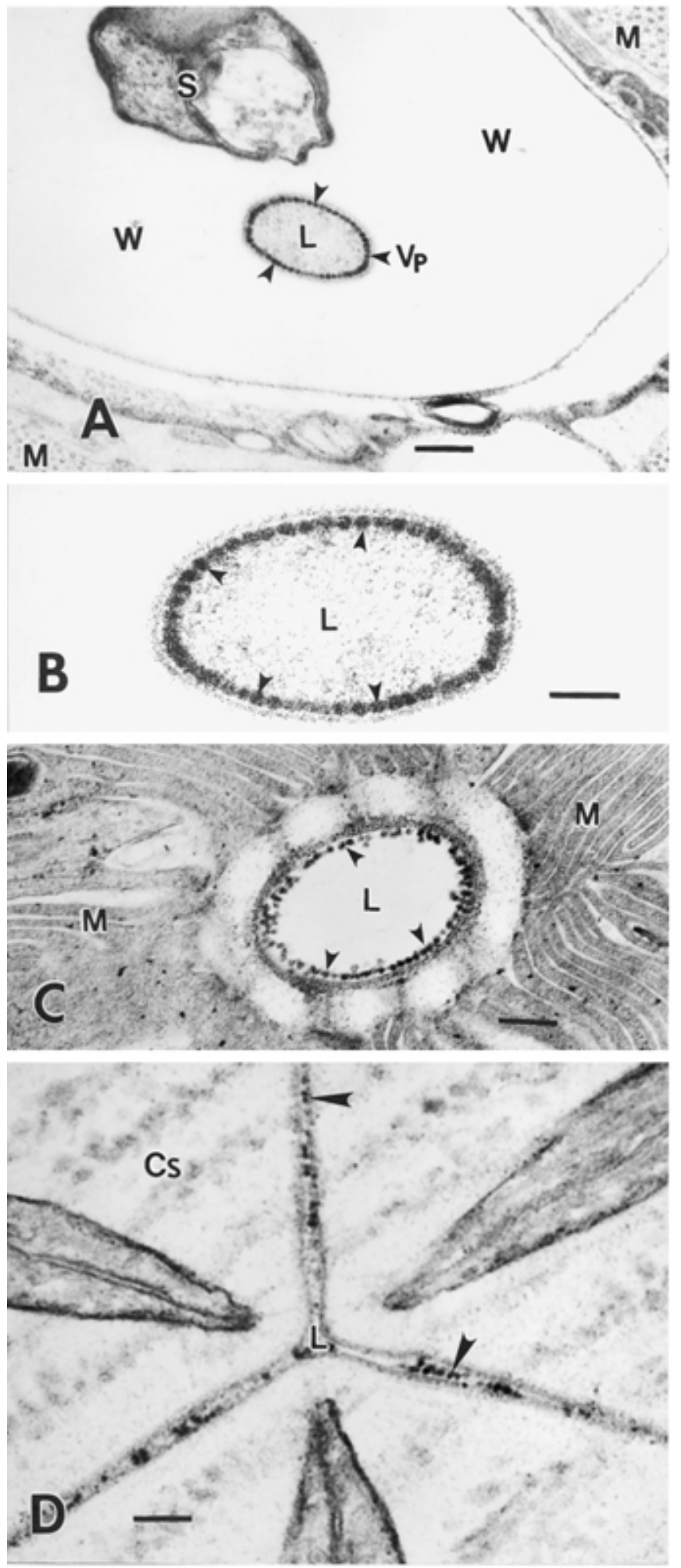

Fig. 2. Electron micrographs from transverse sections of the head region of Tobacco ringspot virus (TRSV)-viruliferous Xiphinema americanum showing the presence of TRSV particles retained in the lumen of different parts of the esophageal tract. A, A low magnification view of the stylet extension showing virus particles (Vp) attached to the inner lining of the lumen (L). S = sinus tissue; $\mathrm{W}=$ stylet wall $\mathrm{M}=$ protractor muscle. Scale bar $=250 \mathrm{~nm}$. $\mathbf{B}$, A higher magnification of the stylet extension lumen in $\mathbf{A}$ showing the details of virus particles (arrowheads) aligned against the inner wall of the lumen (L). Scale bar $=100 \mathrm{~nm}$. C, Cross section of the anterior region of the esophagus showing TRSV particles (arrowheads) along the inner wall of the lumen (L). $\mathrm{M}=$ radial muscle. Scale bar $=250 \mathrm{~nm}$. D, Esophageal bulb region showing triradiate lumen in which a few TRSV particles (arrowheads) are located. $\mathrm{Cs}=$ cuticular stoma. Scale bar $=250 \mathrm{~nm}$. 
Among fragments with head regions that had been labeled with fluorescence, approximately $59 \%$ of the fragments were labeled in the stylet extension, $68 \%$ in the anterior esophageal lumen, and only $7.8 \%$ in the triradiate lumen. If a fragment contained more
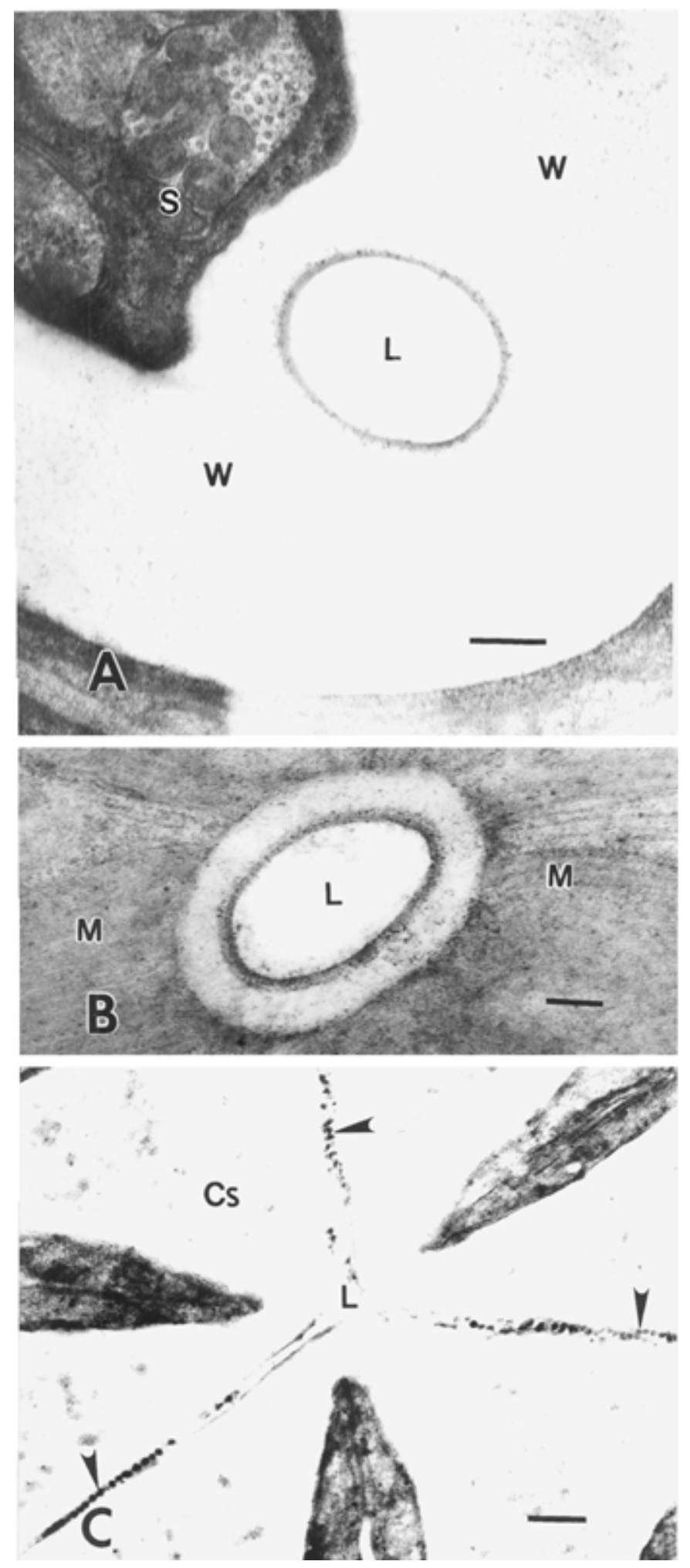

Fig. 3. Electron micrographs from transverse sections of the head region of Tomato ringspot virus (TomRSV)-viruliferous Xiphinema americanum showing the presence or absence of virus particles in the lumen of different parts of the esophageal tract. A, Stylet extension showing no TomRSV particles in the lumen $(\mathrm{L}) . \mathrm{S}=$ sinus tissue; $\mathrm{W}=$ stylet wall. Scale bar $=250 \mathrm{~nm}$. B, Anterior region of esophagus showing no TomRSV particles in the lumen (L). $\mathrm{M}=$ radial muscle. Scale bar $=250 \mathrm{~nm}$. C, Triradiate lumen (L) of esophageal bulb showing the presence of TomRSV particles (arrowheads). $\mathrm{Cs}=$ cuticular stoma. Scale bar $=250 \mathrm{~nm}$. than one area of the head region that was labeled, for example if both the stylet extension and the anterior esophageal lumen displayed fluorescence, these were scored independently for each section of the fragment. The total number of fragments expressing fluorescence in a particular section was divided by the total fragments expressing fluorescence to give the percentage of the total fluorescing sections represented by that particular section. Virusspecific fluorescence was not observed in nematodes that had access to roots of cucumber plants infected by TomRSV, CLRV, or SqMV, although parallel tests with TRSV consistently resulted in immunofluorescent labeling (data not shown).

Retention status of TRSV, TomRSV, CLRV, and SqMV in $X$. americanum as detected by electron microscopy. TRSV particles were frequently observed (in 16 of 40 nematodes examined) in a layer around the inner surface of the lumen of both the stylet extension (Fig. 2A and B) and the anterior esophageal lumen (Fig. 2C), but were observed in the triradiate lumen of the esophageal bulb in only 1 of the 40 nematodes that were examined (Fig. 2D). In contrast, TomRSV particles were not observed in the stylet extension or in the anterior esophageal lumen, but were observed only in the triradiate lumen of the esophageal bulb (virus particles were observed in 20 of the 50 specimens examined) in which virus particles were not abundant and appeared to be sparsely distributed (Fig. 3C). CLRV particles were not observed in any part of the nematode head region (Fig. 4A) of the 40 specimens that were examined. SqMV particles were apparently localized in the triradiate lumen of the esophageal bulb in 28 of 40 specimens observed, but the particles appeared to be partially degraded or embedded in a substance based on their irregular shape and indistinct appearance (Fig. 4C). Particles were not observed in nematodes that had fed on healthy cucumber seedlings (data not shown).

Time course of release of TRSV particles from $X$. americanum. Viruliferous populations of $X$. americanum initially transmitted TRSV at a level of 60 to $75 \%$ but gradually lost this ability within 7 weeks when they were placed on the roots of Sudan grass (Table 2). In concordance with transmission tests, the percentage of viruliferous nematodes detected by immunofluorescent labeling decreased gradually over 7 weeks and no immunofluorescent label was detected after the nematodes had been given access to Sudan grass for 10 weeks. At a population level, the percentage of fluorescence decreased at a similar rate in the stylet extension, the anterior esophageal lumen, and the triradiate lumen during the 10 weeks of access to Sudan grass (Table 3).

\section{DISCUSSION}

The retention status of four viruses with different vector relationships in $X$. americanum were determined with TRSV and TomRSV being readily transmitted but TRSV consistently transmitted less than TomRSV in parallel tests. The transmission efficiency for TRSV in this study, when 10 nematodes were used in transmission experiments, was always $75 \%$ or less as reported in previous tests (33), whereas TomRSV was always transmitted at $100 \%$ efficiency in similar tests. Nematode transmission tests conducted throughout this study gave consistent levels of transmission for TRSV and TomRSV, despite the fact that these viruses were maintained by mechanical inoculation. There is no evidence to suggest that the transmission of nepoviruses is reduced after repeated mechanical transmission as occurs with the nonpersistently transmitted potyviruses. With another sibling species, X. bricolensis, collected from British Colombia, Canada, TomRSV was transmitted with $100 \%$ efficiency when only five nematodes were used in transmission tests, but TRSV was not transmitted (S. Wang and R. C. Gergerich, unpublished data), confirming an earlier report (4) that X. bricolensis is not a vector of TRSV.

Electron microscopy revealed that TRSV was primarily localized in the regions of the stylet extension and anterior esophageal 
lumen, and only rarely in the region of the esophageal bulb. This was confirmed by immunofluorescent labeling that showed a much higher frequency of fluorescence in the stylet extension and the anterior esophageal lumen than in the triradiate lumen of the esophageal bulb in populations of viruliferous nematodes. In contrast, TomRSV was retained in the triradiate lumen but not in the stylet extension and anterior esophageal lumen, which were the binding sites for TRSV. The existence of different binding sites for these two viruses in the same nematode may explain the dual transmission of both TRSV and TomRSV by single $X$. americanum nematodes (9) because each virus is bound at a unique site and therefore may not compete with the other virus for attachment.

Different binding sites for these two viruses may reflect significant differences in the mechanism involved in the release of virus particles. TRSV particles retained in the stylet extension and anterior esophageal lumen may be released by the action of dorsal gland secretions during feeding, or alternatively by the subventral gland secretions. However, because TomRSV was retained only in the triradiate lumen, it may be that only secretions from the subventral glands, and not those of the dorsal gland, mediate the release of this virus. If different types of secretions do mediate virus release, this may contribute to the difference in transmission efficiency of these two viruses.

CLRV was previously reported to be transmitted by X. coxi (7), $X$. diversicaudatum (6), X. vuittenezi (6), and several Longidorus spp. (17). However, this virus is not considered to be a nematode transmissible nepovirus, or at least its specific association with nematode vectors has not been verified (4). Our study confirms that $X$. americanum is not a vector of CLRV, and that the lack of transmission appears to be due to the absence of virus attachment in the head region of this nematode. Interestingly, SqMV, a comovirus naturally transmitted by leaf-feeding beetles (11) but not by $X$. americanum, appeared to be attached in the triradiate lumen of
$X$. americanum although the shape of virus particles was somewhat irregular. The degraded appearance of the SqMV particles may be due to the action of proteases in the esophageal tract of the nematode because comoviruses, including SqMV, have been shown to be partially degraded by proteases in insects without affecting the infectivity of the viruses (20). Serologically distinguishable strains of Tobacco rattle virus (TRV) have different sites of retention in its trichodorid nematode vector, and particles of nontransmissible strains of TRV have been observed in trichodorid nematodes that are not vectors of these TRV strains (18). No

TABLE 2. Transmission and retention of Tobacco ringspot virus (TRSV) by Xiphinema americanum over time as measured by transmission trials and immunofluorescent labeling, respectively

\begin{tabular}{lccccc}
\hline \multirow{2}{*}{$\begin{array}{l}\text { Time on } \\
\text { Sudan grass }^{\mathrm{a}}\end{array}$} & \multicolumn{2}{c}{$\%$ Transmission $^{\mathrm{b}}$} & & \multicolumn{2}{c}{$\%$ Virus retention $^{\mathrm{c}}$} \\
\cline { 2 - 3 } \cline { 5 - 6 } & Experiment 1 & Experiment 2 & & Experiment 1 & Experiment 2 \\
\hline 0 & 75 & 60 & & 40.2 & 27.3 \\
1 week & 53 & - & & 23.2 & - \\
2 weeks & 56 & 56 & & 13.7 & 18.4 \\
3 weeks & 46 & 28 & & 11.9 & 12.4 \\
7 weeks & 0 & 0 & & 1.1 & 1.7 \\
10 weeks & 0 & 0 & 0 & 0 \\
\hline
\end{tabular}

a Nematodes were given access to TRSV-infected cucumbers for 10 days after which they were placed on Sudan grass until assayed for virus transmission and retention.

${ }^{\mathrm{b}}$ For each transmission test, groups of 10 nematodes were added to the roots of single cucumber seedlings, and 3 weeks later the roots of the cucumber were assayed for virus on cucumber and cowpea seedlings. A minimum of 20 groups was tested in each experiment. Percentages are plants testing positive for virus.

Groups of 200 nematodes were evaluated for virus retention by immunofluorescent labeling for each test in each experiment. Percentages are the number of fluorescing nematode fragments in every 100 fragments with virus retention sites.
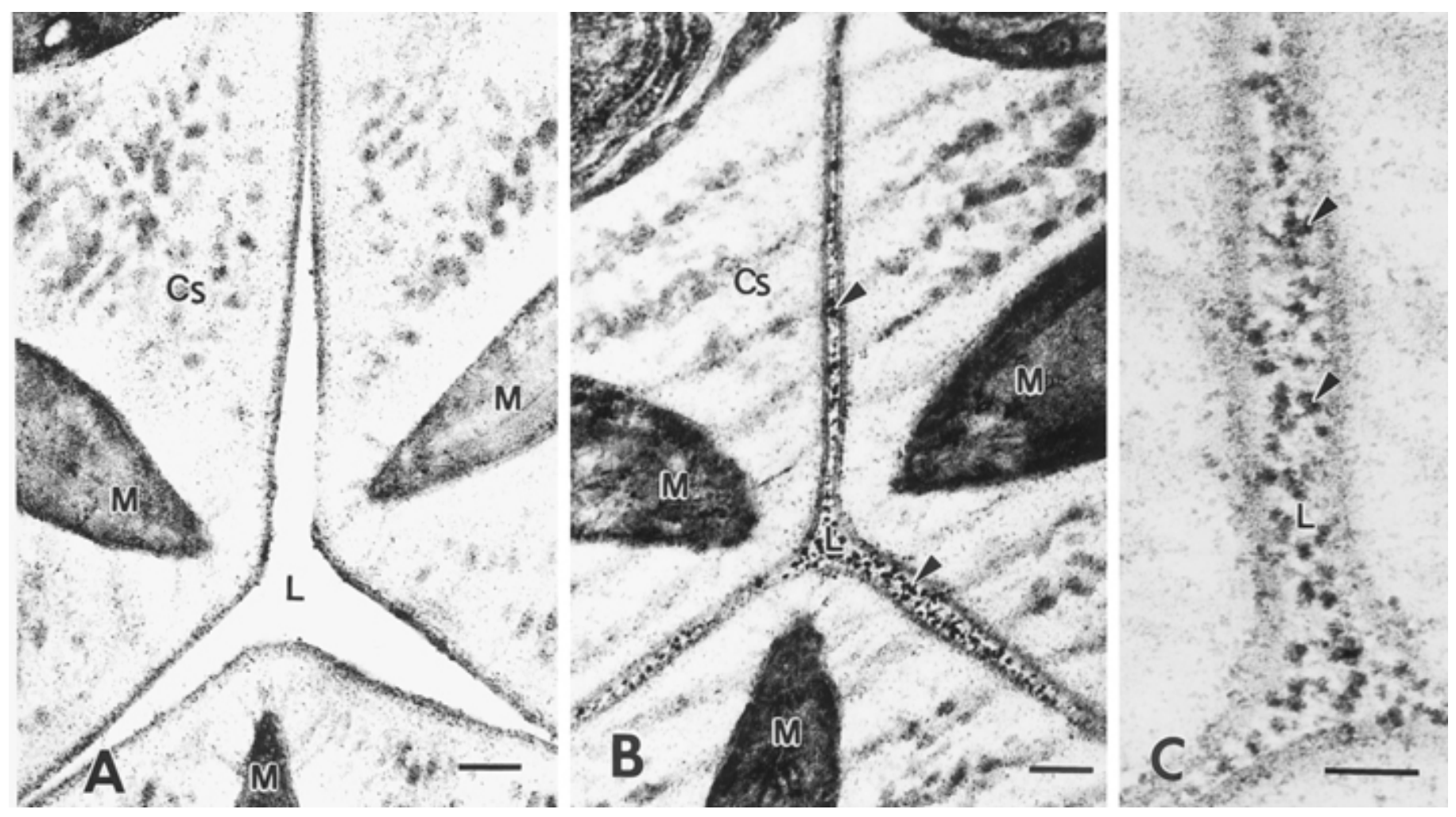

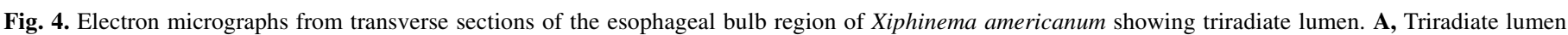

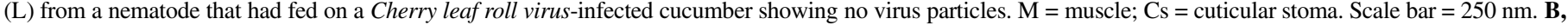

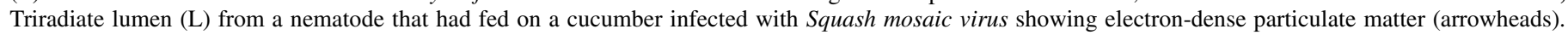

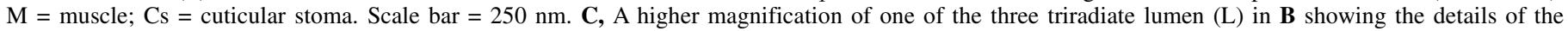
particulates (arrowheads) which are ill-defined and irregularly shaped compared with virus particles. Scale bar $=100 \mathrm{~nm}$. 
information is available at this time regarding the transmission efficiency or localization of different strains of TRSV in $X$. americanum.

The monitoring of virus release from vector nematodes previously has not been studied principally because of the lack of an in situ detection technique that can be used to quantify virus disassociation at a population level. Immunofluorescent labeling of nematode fragments makes it possible to monitor the length of time the virus is retained at different sites in the nematode. This study demonstrated that TRSV was similarly retained in X. americanum at the retention regions observed (Table 3 ). This result confirms previous observations by McGuire (24) that $X$. americanum populations maintain transmissibility for extended periods. As suggested by Brown et al. (4), the slow dissociation of viruses within the vector nematodes could provide an ecologically advantageous mechanism for successful virus transmission by nematodes. Another significant finding of this study is that complete release of virus particles retained in the esophageal tract of nematode populations, as measured by immunofluorescent microscopy, was associated with loss of transmission by a population of nematodes. Thirdly, the percentage of viruliferous nematodes in a population detected by immunofluorescent labeling was closely correlated to actual virus transmission (Table 2), suggesting that this may be used as a routine technique to determine the transmission status of a given population instead of using time-consuming greenhouse transmission trials which usually take several weeks.

There are three possible explanations why immunofluorescent labeling did not detect viruses except TRSV in the vector nematode. Firstly, virus particles may not be bound to any part of nematode esophageal tract, such as the case with CLRV. Secondly, virus particles retained in the nematode esophageal tract might be either partially degraded by or coated with other components from nematode gland cells or other sources such as host plants. Any degradation or coating could eliminate or block the physical binding between virus particles and antibody molecules. Thirdly, virus concentration in the retention site might be too low to be detected. This explanation could apply to TomRSV, because few particles of this virus were in the nematode esophageal tract when observed in thin-section electron microscopy, even though this virus is transmitted by $X$. americanum very efficiently. Robertson (W. M. Robertson, unpublished data) suggests that with European longidorid vector nematodes, the more efficiently the virus is transmitted, the fewer virus particles are observed at sites of retention. This may also occur with $X$. americanum. The reason for high transmissibility despite lower virus retention could be that TomRSV is more readily released from retention sites. In contrast, TRSV may be bound much more tightly in the stylet extension and anterior esophageal lumen and therefore less efficiently trans-

TABLE 3. Retention of Tobacco ringspot virus (TRSV) in the stylet extension, anterior esophageal lumen, and triradiate lumen of Xiphinema americanum after feeding on Sudan grass, a nonhost for the virus

\begin{tabular}{lccc}
\hline \multirow{2}{*}{$\begin{array}{l}\text { Time on } \\
\text { Sudan grass }\end{array}$} & \multicolumn{2}{c}{ Percentage of fragments displaying fluorescence } \\
\cline { 2 - 4 } & Stylet extension & Esophageal lumen & Triradiate lumen \\
\hline 0 week & 20.4 & 23.6 & 1.2 \\
1 week & 11.6 & 14.3 & 1.7 \\
2 weeks & 13.6 & 7.3 & 0.25 \\
3 weeks & 10.2 & 6.8 & 0 \\
7 weeks & 1.4 & 0 & 0 \\
10 weeks & 0 & 0 & 0 \\
\hline
\end{tabular}

a Nematodes were given access to TRSV-infected cucumbers for 10 days after which they were placed on Sudan grass until assayed for virus retention.

${ }^{b}$ Groups of 200 nematodes were evaluated for virus retention by immunofluorescent labeling in two experiments. Percentages represent the number of fragments displaying virus-specific fluorescence over the total number of fragments examined for each virus retention site. Data are the averages of two experiments. mitted. This appears to be the case with Raspberry ringspot virus (RRSV), which is transmitted infrequently by Longidorus macrosoma despite the fact that nematodes given access to RRSV contain large numbers of virus particles in the lumen of their odontostyle (4). The high number of TRSV particles bound to retention sites (as observed by electron microscopy) results in a strong fluorescent signal. The failure to detect TomRSV with immunofluorescent labeling suggests differences between TomRSV and TRSV in the mechanism of association with their nematode vector $X$. americanum.

Effective binding of virus particles to the nematode esophageal tract is an essential phase of the transmission process. This study with two nontransmissible viruses indicates that binding also occurs with viruses other than nepoviruses. The fate of nontransmissible viruses in vector nematodes can be either direct passage to the intestine without any binding to the anterior digestive tract or temporary retention followed by degradation or release into the posterior digestive tract.

\section{ACKNOWLEDGMENTS}

This research was supported in part by grant 2001-35302-09980 from the U.S. Department of Agriculture, National Research Initiative, Competitive Grants Program, and the Arkansas Agricultural Experiment Station Research Incentive Grants Program. We thank S. C. Goeke and $\mathrm{H}$. Tian for technical assistance in electron microscopy.

\section{LITERATURE CITED}

1. Breece, J. R., and Hart, W. H. 1959. A possible association of nematodes with the spread of peach yellow bud mosaic virus. Plant Dis. Rep. 43:989-990.

2. Brown, D. J. F., and Boag, B. 1988. An examination of methods used to extract virus-vector nematodes (Nematoda: Longidoridae and Trichodoridae) from soil samples. Nematol. Mediterr. 16:93-99.

3. Brown, D. J. F., Halbrendt, J. M., Jones, A. T., Vrain, T. C., and Robbins, R. T. 1994. Transmission of three North American nepoviruses by populations of four distinct species of the Xiphinema americanum group. Phytopathology 84:646-649.

4. Brown, D. J. F., Robertson, W. M., and Trudgill, D. L. 1995. Transmission of viruses by plant nematodes. Annu. Rev. Phytopathol. 33:223249.

5. Cobb, N. A. 1913. New nematode genera found inhabiting fresh water and nonbrackish soils. J. Wash. Acad. Sci. 3:432-444.

6. Flegg, J. J. M. 1969. Tests with potential nematode vectors of cherry leaf-roll virus. East Malling Res. Stn. Rep. 1968:155-157.

7. Fritzche, R., and Kegler, H. 1964. Die hubertragung des blattrolvirus der kirsche (cherry leaf-roll virus) durch nematoden. Naturwissenschaften $51: 299$.

8. Fulton, J. P. 1962. Transmission of tobacco ringspot virus by Xiphinema americanum. (Abstr.) Phytopathology 52:375.

9. Fulton, J. P. 1967. Dual transmission of tobacco ringspot virus and tomato ringspot virus by $X$. americanum. Phytopathology 57:535-537.

10. Gergerich, R., Asher, J. H., Jr., and Ramsdell, D. C. 1983. A comparison of some serological and biological properties of seven isolates of tobacco ringspot virus. Phytopathol. Z. 107:289-300.

11. Gergerich, R. C., and Scott, H. A. 1996. Comoviruses: Transmission, ecology and control. Pages 77-98 in: The Plant Viruses: Viruses with Bipartite RNA Genomes. B. D. Harrison and A. F. Murant, eds. Plenum Press, New York.

12. Halbrendt, J. M. 1993. Virus-vector Longidoridae and their associated viruses in the Americas. Russ. J. Nematol. 1:65-68.

13. Harrison, B. D., and Murant, A. F. 1978. Nematode transmissibility of pseudorecombinant isolates of tomato black ring virus. Ann. Appl. Biol. 86:209-212.

14. Harrison, B. D., Murant, A. F., Mayo, M. A., and Roberts, I. M. 1974. Distribution and determinants for symptom production, host range and nematode transmissibility between the two RNA components of raspberry ringspot virus. J. Gen Virol. 22:233-247.

15. Harrison, B. D., Robertson, W. M., and Taylor, C. E. 1974. Specificity of retention and transmission of viruses by nematodes. J. Nematol. 6:155164.

16. Hirumi, H., Chen, T. A., Lee, K. J., and Maramorosch, K. 1968. Ultrastructure of the feeding apparatus of the nematode Trichodorus christiei. J. Ultrastruct. Res. 24:434-453. 
17. Jones, A. T., McElroy, F. D., and Brown, D. J. F. 1981. Tests for transmission of cherry leaf roll virus using Longidorus, Paralongidorus and Xiphinema nematodes. Ann. Appl. Biol. 99:143-150.

18. Karanastasi, E., MacFarlane, S. A., Wyss, U., and Brown, D. J. F. 2001. Studies of the acquisition, retention, and transmission of tobraviruses by virus-vector (Para) Trichodorids. (Abstr.) Phytopathology 91(suppl.):S46.

19. Klos, E. J., Fronek, F., Knierim, J. A., and Cation, D. 1967. Peach rosette mosaic transmission and control studies. Mich. Agric. Exp. Stn. Q. Bull. 49:287-293.

20. Langham, M. A. C., Gergerich, R. C., and Scott, H. A. 1990. Conversion of comovirus electrophoretic forms by leaf-feeding beetles. Phytopathology 80:900-906.

21. Larsen, R. C., Gergerich, R. C., and Kim, K. S. 1990. Characterization and ultrastructural studies of a nepovirus from Euonymus. Phytopathology 80:134-140.

22. MacFarlane, S. A., and Brown, D. J. F. 1995. Sequence comparison of RNA-2 of nematode-transmissible and nematode-non-transmissible isolates of pea early-browning virus suggests that the gene encoding the $29 \mathrm{kDa}$ protein may be involved in nematode transmission. J. Gen. Virol. 76:1299-1304.

23. MacFarlane, S. A., Wallis, C. V., and Brown, D. J. F. 1996. Multiple virus genes involved in the nematode transmission of pea early browning virus. Virology 219:417-422.

24. McGuire, J. M. 1973. Retention of tobacco ringspot virus by Xiphinema americanum. Phytopathology 63:324-326.

25. McGuire, J. M., Kim, K. S., and Douthit, L. B. 1970. Tobacco ringspot virus in the nematode Xiphinema americanum. Virology 42:212-216.

26. Murant, A. F., Jones, A. T., Martelli, G. P., and Stace-Smith, R. 1996. Nepoviruses: General properties, diseases and virus identification. Pages 99-137 in: The Plant Viruses, Vol. 5: Polyhedral Virions and Bipartite RNA Genomes. B. D. Harrison and A. F. Murant, eds. Plenum Press, New York.

27. Nyland, G., Lownsbery, B. F., Lowe, B. K., and Mitchell, J. F. 1969. The transmission of cherry rasp leaf virus by Xiphinema americanum. Phytopathology 59:1111-1112.

28. Ploeg, A. T., Brown, D. J. F., and Robinson, D. J. 1993. RNA-2 of tobacco rattle virus encodes the determinants of transmissibility by trichodorid vector nematodes. J. Gen. Virol. 74:1463-1466.

29. Robbins, R. T. 1993. Distribution of Xiphinema americanum and related species in North America. J. Nematol. 25:344-348.

30. Robertson, W. M., and Henry, C. E. 1986. An association of carbohydrates with particles of arabis mosaic virus retained within Xiphinema diversicaudatum. Ann. Appl. Biol. 109:299-305.

31. Trudgill, D. L., and Brown, D. J. F. 1978. Ingestion, retention and transmission of two strains of raspberry ringspot virus by Longidorus macrosoma. J. Nematol. 10:85-89.

32. Trudgill, D. L., Brown, D. J. F., and McNamara, D. G. 1983. Methods and criteria for assessing the transmission of plant viruses by longidorid nematodes. Rev. Nematol. 6:133-141.

33. Wang, S., and Gergerich, R. C. 1998. Immunofluorescent localization of tobacco ringspot nepovirus in the vector nematode Xiphinema americanum. Phytopathology 88:885-889. 